Research Article

\title{
Jet Milling as an Alternative Processing Technique for Preparing Polysulfone Hard Nanocomposites
}

\author{
Amaia Llorente, ${ }^{1}$ Berna Serrano ${ }^{(D)},{ }^{1}$ Juan Baselga, ${ }^{1}$ Gabriel Gedler, ${ }^{2}$ and Rahmi Ozisik ${ }^{2}$ \\ ${ }^{1}$ Department of Materials Science and Engineering \& Chemical Engineering, Polytechnic School (IAAB), \\ Carlos III University of Madrid, Avda Universidad 30, 28911 Leganes, Madrid, Spain \\ ${ }^{2}$ Department of Materials Science and Engineering, Rensselaer Polytechnic Institute, Troy, NY 12180, USA
}

Correspondence should be addressed to Berna Serrano; berna@ing.uc3m.es

Received 14 December 2018; Accepted 6 February 2019; Published 26 February 2019

Academic Editor: Youhong Tang

Copyright (c) 2019 Amaia Llorente et al. This is an open access article distributed under the Creative Commons Attribution License, which permits unrestricted use, distribution, and reproduction in any medium, provided the original work is properly cited.

\begin{abstract}
This work describes how a solid-state blending method such as jet milling can be used to successfully prepare polysulfone (PSU)/ $\gamma$-alumina nanocomposites. For comparison purposes, conventional melt extrusion was used as well. Morphological analysis revealed how jet mill blending allows obtaining well-dispersed $\gamma$-alumina nanoparticles within a polysulfone matrix without any surface treatment, with an important decrease of particle size promoted by the breakup of agglomerates and aggregates due to the particle-particle impacts during processing, which was not observed in the extruded nanocomposites. DSC analysis demonstrated that jet-milling processing promoted $T_{\mathrm{g}}$ enhancements with alumina addition, while TGA experiments confirmed the increment of thermal stability of the nanocomposites prepared by jet milling when compared with the composites prepared by extrusion. The tensile tests showed that ductility remains at a high value for milled nanocomposites, which agreed with the fracture surface images revealing large plastic deformation as a function of the alumina content. This comparative study indicates that the dispersion of nanoparticles in PSU was more homogeneous, with smaller nanoparticles when preparing nanocomposites using jet milling, showing a strong correlation with the enhanced final properties of the nanocomposites.
\end{abstract}

\section{Introduction}

The greatest problem to the large-scale industrial production of polymer nanocomposites is the absence of methods to prepare uniform and stable dispersions of nanoparticles in polymer matrices in a fast manner. It is well demonstrated that tuning the dispersion of inorganic nanoparticles within polymer matrices favors the composite fabrication and optimizes polymer nanocomposite properties [1]. Nevertheless, to get a very good dispersion of nanoparticles into a polymer matrix is intrinsically difficult due to their strong enthalpic incompatibility. A large number of authors have proposed surface ligand engineering of the nanofiller to improve the compatibility between the nanofillers and the polymer matrix. Appropriate chemical engineering treatment of the nanofiller surface could improve both the strength and toughness of the composites. Li and co-authors [2] summarized the work focused on surface ligand engineering, from small molecules to the most complex modifications, and highlighted applications that can benefit from surface nanofiller modification, principally from spherical inorganic nanoparticles, which are the type of nanofillers most used to enhance performance of nanocomposites. The interfacial interactions play a crucial role in determining the quality and properties of the nanocomposites. Monodisperse and multimodal attachment of polymer chains to nanoparticle have been studied extensively to enhance compatibility in polymeric matrixes [3-8]. As a special type, Rungta et al. [9] successfully designed a bimodal polymer brush that contains a small number of long homopolymer chains that can entangle with the polymer matrix and a high density of short brushes that screen the core/core van der Waals 
interactions between the nanoparticles. Although the ability to disperse grafted nanoparticles in a polymer matrix is of great importance for optimizing the performance of polymer nanocomposites, under certain conditions of graft density and graft/polymer molecular weight ratio, nanoparticles tend to aggregate into clusters or to form phase separated domains when they are immersed in melts [10]; consequently, the property of the nanocomposites which might arise due to their nanoscale dimensions vanishes. Moreover, the surface modification is often chemically very complex, and in some cases, macromolecular grafting to nanoparticles can result in complex morphologies which can add further complication to the dispersion [7]. Nowadays, despite the huge scientific and technological activity, major challenges remain in polymer nanocomposites, especially related to nanoparticle dispersion via industrially scalable and environmental friendly methods.

The available techniques to fabricate strong nanocomposites are melt mixing, casting, and dry powder blending. Among them, melt shearing mixing methods have proven to be most effective. However, this approach is precluded for some polymer matrices that are difficult to work with, giving limited stresses that are insufficient to achieve nanofiller dispersions in polymers, especially when hard nanoparticles are used. Blending polymer and nanoparticles in solvent can lead to better dispersion but are not environmentally friendly methods and have limited applicability and scalability.

Recently dry powder blending methods have been successfully developed for processing polymer nanocomposites. These techniques include ball and pan milling [11] and solid-state shear pulverization (SSSP) [12]. In past, SSSP has been used to produce polymeric materials that are difficult or impossible to produce via conventional melt processing. However, recently several studies have showed that it is possible to achieve very good nanofiller dispersion $[13,14]$, even superior to that obtained with conventional melt processing. Well-dispersed polypropylene nanocomposites were made with up to 8 or $9 \mathrm{wt} \%$ pristine nanosilica and modified nanosilica by SSSP with $\sim 10$ $100 \mathrm{~nm}$ size-range nanofiller. Compared to the neat polypropylene, unmodified nanosilica hybrids showed superior Young's modulus and tensile strength, consistent with a very good dispersion. That is to say, well-dispersed unmodified nanofiller can result in more robust nanocomposites than when modified nanofiller is used to compatibilize the polymer nanofiller interface.

In addition, compared with other conventional methods, dry blending methods are especially suitable and advantageous for the fabrication of biocomposites, resulting not only in an excellent dispersion but also a suppression of filler degradation due to high-temperature melt processing. For example, polyolefin biocomposites using cellulose nanocrystal [15] and waste paper [16] as fillers were prepared by solid-state shear pulverization leading superior dispersion relative to neat polymer and consequently improvements in properties.

Here, we employ a solventless and scalable technique called jet milling to produce well-dispersed polymer/ unmodified alumina nanoparticle nanocomposites. Jet milling is a well-known machining technique for processing materials that can be performed in wet and dry conditions. Folkes [17] has reviewed the range of materials that can be processed by wet jet milling and the geometries that can be formed with this technique. Dry jet milling is conventionally used for size reduction of dry materials producing powders with sizes between 1 and 10 microns. An application example has been reported by Palaniandy et al. [18], who studied the mechanochemical effects of the grinding technique on silica. Dry jet milling is also an attractive blending technique because the high shearing forces may result in effective disbanding of nanoparticle agglomerates in the presence of a polymer. However, it has not been used up to date to process amorphous polymer nanocomposites. To the authors' knowledge, only Sawyer et al. [19] reported the use of dry jet milling for preparing PTFE/alumina composites with a modest success; the high tendency for crystallization of PTFE chains competed with nanoparticle disbanding resulting in an exclusion of the particles from the crystalline domains and its probable reaggregation.

The benefit of mechanical solid processing is the production of nanocomposite powder which can be further processed using industrially scalable melt processing techniques. In this work, the jet mill machine is used as a blending technique to disperse $\gamma$-alumina hard nanoparticles into a high-performance polymer: polysulfone. We show the effects of dry jet milling on agglomerates disbanding without chemical modification of the hard nanofiller surface or the use of very high temperatures. Nanocomposites have been also fabricated by melt extrusion to compare both blending methods, and remarkable enhancements on the dispersion degree and mechanical behavior were found using jet milling.

\section{Experimental}

2.1. Materials. $\gamma$-Alumina nanoparticles (average diameter $\leq 50 \mathrm{~nm}$ as reported by the manufacturer) were purchased from Sigma-Aldrich. The specific surface area of $180 \mathrm{~m}^{2} \mathrm{~g}^{-1}$ was determined by the BET method. Dynamic light scattering measurements (NanoZS90Zetasizer, Malvern), in aqueous dispersion (0.01 wt.\%) at $\mathrm{pH}=3$ and $25^{\circ} \mathrm{C}$, indicates an average size of $130 \pm 5 \mathrm{~nm}$, higher than those specified by SigmaAldrich. A commercial polysulfone (Sigma-Aldrich) with $M_{n}=16000^{\circ} \mathrm{gmol}^{-1}$ and $M_{\mathrm{w}}=35000^{\circ} \mathrm{gmol}^{-1}$ was used as the matrix polymer.

2.2. Preparation of Samples. The jet milling process was performed with a Sturvent Micronizer ${ }^{\circledR}$ which works by particle-on-particle attrition to grind, without presence of heat or wear. Jet-milled nanocomposites were prepared by blending the appropriate masses of polysulfone and $\gamma$-alumina nanoparticles at 2,5 , and $10^{\circ} \mathrm{wt} . \%$ loading; the code used for these samples was PSU_JM. A hand-mixed powder of the constituents was introduced into the milling chamber with a high-speed circumferential flow of dry air. Within the milling chamber, the circular gas stream accelerated the 
particles, which were micronized by high-speed collisions with each other or with the wall of the chamber. As the powder was impacted at high speed, agglomerates were broken and the nanoparticles were incrusted into softer polymer particles. Centrifugal forces drove the biggest powder particles to the periphery of the chamber for further grinding, and the smaller particles were collected in a metallic vessel. Mixtures were passed through three times to confirm a perfect dispersion of nanopowder under pressure grinding air and filling air of 60 and 24 psi, respectively. For comparison, neat PSU was subjected to the same milling process.

Comparable nanocomposites were also prepared at 2, 5, and $10^{\circ}$ wt.\% loadings by microextrusion in a Haake Minilab microcompounder (codes were PSU_Ext) at a processing temperature of $360^{\circ} \mathrm{C}$, recirculation time $10 \mathrm{~min}$, and screw rotating speed $150 \mathrm{rpm}$.

Mini-bone shaped specimens $16 \times 3 \times 1 \mathrm{~mm}^{3}$ of both types of premixes (PSU_JM and PSU_Ext) were prepared for tensile testing by a subsequent injection process (Battenfeld Microsystem 50 microholding machine) with a mold temperature of $135^{\circ} \mathrm{C}$, injection temperature of $345^{\circ} \mathrm{C}$, and pressure of $500 \mathrm{bar}$, as described in our previous paper [20].

2.3. Characterization. The glass transition temperatures $\left(T_{\mathrm{g}}\right)$ of both PSU and the nanocomposites were determined using a Mettler Toledo 822 Differential Scanning Calorimeter (DSC). $5-10 \mathrm{mg}$ of the samples were hermetically sealed in aluminum pans and measured in the range $25-225^{\circ} \mathrm{C}$ at $10^{\circ} \mathrm{C} \mathrm{min}^{-1}$ under $10 \mathrm{ml} \cdot \mathrm{min}^{-1} \mathrm{~N}_{2}$. Thermogravimetric analysis (TGA) was carried out using a TGA Perkin Elmer STA 6000 . Samples ranging from 15 to $20 \mathrm{mg}$ were heated from 50 to $900^{\circ} \mathrm{C}$ at a rate of $10^{\circ} \mathrm{C} \mathrm{min}^{-1}$ in a dry air atmosphere.

Tensile tests were performed on a Shimadzu Autograph AG-1 universal testing machine at room temperature at an extension rate of $1 \mathrm{~mm} \cdot \mathrm{min}^{-1}$. Before testing, all specimens were kept at $150^{\circ} \mathrm{C}$ for 1 hour to remove residual stresses.

A Field Emission SEM (FEI Nova NANOSEM 230) was used to characterize the cryofractured surfaces of the nanocomposites using a voltage of $5 \mathrm{kV}$ and a working distance of $3.5 \mathrm{~mm}$; some samples were also observed with a Philips XL30 SEM using a voltage of $20 \mathrm{kV}$ and a working distance of $10.5 \mathrm{~mm}$. Confocal laser scanning microscope (CLSM) observations on the injected specimens were carried out using an inverted microscope (LSM 5 PASCAL, Carl Zeiss, Germany) with a $458 \mathrm{~nm}$ Ar laser in the reflection mode to quantify nanoparticle size distribution.

\section{Results and Discussion}

3.1. Jet-Mill Powder Blending. Representative SEM images of original $\gamma$-alumina nanoparticles in Figure 1(a) evidenced the presence of micron-sized aggregates. Jet-milling processing favors the breakage of aggregates due to particle-onparticle impacts [21]; this effect is clearly observed in Figure 1(b), which displays the presence of bright submicron alumina nanoparticles "decorating" the PSU particles surface; average size of these nanoparticles was $60 \pm 5 \mathrm{~nm}$, confirming qualitatively that the jet-milling method effectively disaggregated the original agglomerates of $\gamma$-alumina nanoparticles. Similar results have been previously shown in PTFE/alumina composites also prepared by jet milling [22].

\subsection{Effect of Processing on the Glass Transition Temperature.} Glass transition temperature $\left(T_{\mathrm{g}}\right)$ is considered a thermal property of a polymer sensitive to the addition of nanofillers and processing conditions [23]. Deviations in the $T_{\mathrm{g}}$ of the nanocomposite system with respect to neat polymer matrix depend on the dispersion state as well as on the chemical and physical interfacial interactions between the nanofiller surface and the surrounding polymer matrix [24]. Figure 2 shows $T_{\mathrm{g}}$ values for neat PSU and PSU_Ext, and PSU_JM at different loadings.

The $T_{\mathrm{g}}$ of neat PSU as well as the PSU processed by either jet milling or extrusion methods was measured to be $186^{\circ} \mathrm{C}$, suggesting that shearing forces on PSU alone do not modify appreciably the molar mass of the polymer. However, the filler concentration dependency of the $T_{\mathrm{g}}$ for the two sets of nanocomposites showed a completely different behavior: while the $T_{\mathrm{g}}$ of PSU_JM specimens remained constant or increased $2^{\circ} \mathrm{C}$ at high loadings, the $T_{\mathrm{g}}$ of the PSU_Ext specimens clearly presented a decreasing trend. It has been reported that high-energy mechanical milling of polymers can lead to chain scission during the milling process with an important reduction in molecular weight (50\% lower after milling), resulting in a slight decrease in $T_{\mathrm{g}}$ [25]. However, our results show that neat PSU appears to be not sensitive to chain scission. Thus, shifts in $T_{\mathrm{g}}$ can only be attributed to the well-dispersed state of alumina nanoparticles within the PSU matrix which, in the case of jet milling, increased alumina nanoparticle-PSU interactions. This result is consistent with the restrictions on mobility imposed by the nanoparticle-polymer interactions [26]. It is well known that similar increments can be achieved by a suitable modification of the nanoparticles' surface [27]; but, according to previous experience, this is not necessarily the case for alumina nanoparticles [20].

For the extruded nanocomposites (PSU_Ext), the decrease in $T_{\mathrm{g}}$ can be attributed to the presence of large aggregates with an average size of $15 \pm 5 \mu \mathrm{m}$. Following the analysis of Vaziri et al., the presence of large aggregates within the polymer allows the polymer chains to have higher mobility around the region of influence of the aggregates when compared with the mobility in the absence of aggregates [28]; as a consequence, $T_{\mathrm{g}}$ decreases as it can be observed in Figure 2.

However, it should be noted that, in both cases, the absolute increment or decrement of $T_{\mathrm{g}}$ is quite small. This can be explained considering that PSU is a highperformance polymer with excellent thermal properties which are a consequence of its high entanglement density $\left(v e=0.548 \mathrm{mmolcm}^{-3}\right)$ [29]. For this reason, big changes in $T_{\mathrm{g}}$ should not be expected.

3.3. Thermogravimetric Analysis (TGA). Orhan et al. [30] describes the temperature-dependent thermal decomposition 


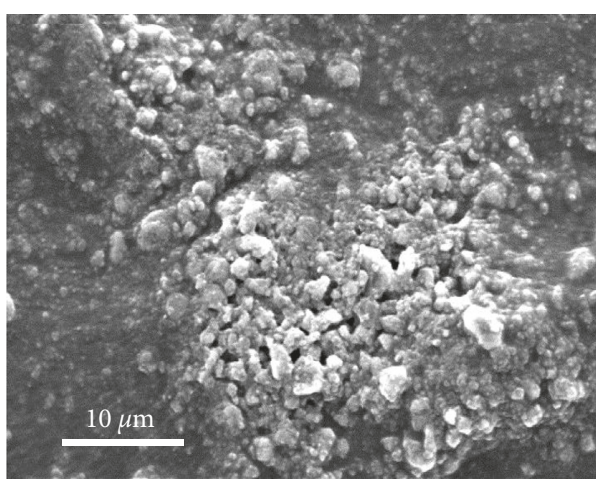

(a)

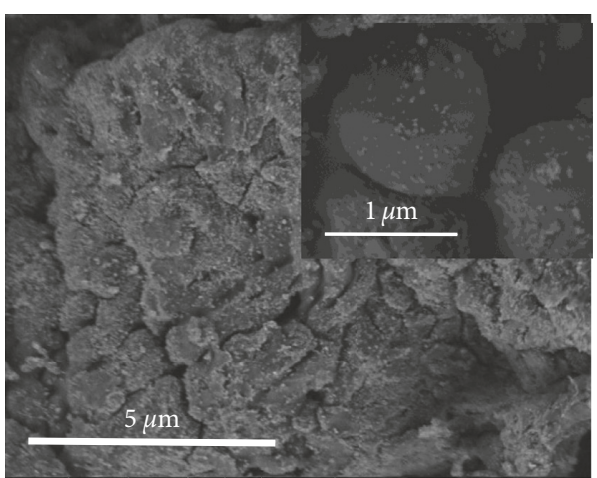

(b)

FIGURE 1: FESEM images of (a) neat alumina and (b) $10 \mathrm{wt} \%$ alumina blended by jet milling with PSU powder, and the inset corresponds to alumina nanoparticles decorating the PSU particles surfaces at different magnifications.

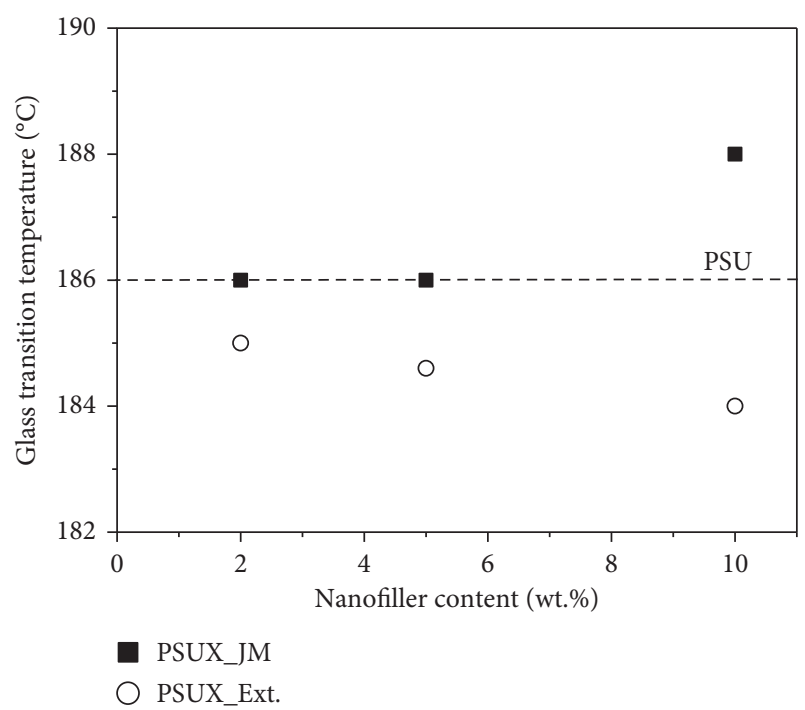

FIGURE 2: Glass transition temperatures collected by DSC from the second heating scan of neat PSU (dotted line), PSU_Ext $(O)$, and PSU_JM ( $\boldsymbol{\square})$ as a function of alumina content.

mechanisms showing the different molecules formed at each stage; however, the major mechanism for PSU thermal degradation is a one-stage pyrolysis involving main-chain random scission and carbonization. Molnár et al. have reported [31] that, in the pyrolysis of PSU at 400 or $500^{\circ} \mathrm{C}$, it is not possible to detect any amount of decomposition products. However, pyrolysis at $600^{\circ} \mathrm{C}$ generates traces of $\mathrm{SO}_{2}$, benzene, and phenol, toluene, styrene, and xylene being the other degradation products that can be identified by pyrolysis gas chromatography coupled with mass spectrometry. Figure 3(a) shows the TGA curves for both PSU_Ext and PSU_JM, where it can be observed that the first main degradation temperature of PSU appears above $500^{\circ} \mathrm{C}$. The shape of both curves is similar, but a slight decrease of thermal stability for PSU_Ext must be noted, compared with PSU_JM; this effect has been attributed to the high temperature (i.e., $360^{\circ} \mathrm{C}$ ) and recirculation time $(10 \mathrm{~min})$ used during extrusion. Figure $3(\mathrm{~b})$ shows the initial decomposition temperature defined as the temperature at $10 \%$ weight loss $\left(T_{\mathrm{i}}\right)$, and Table 1 shows the temperature at the maximum degradation rate $\left(T_{\max }\right)$ for both PSU and the nanocomposites.

It can be observed that addition of bare alumina at high loadings (i.e., 5 and $10 \mathrm{wt} . \%$ ) had a detrimental effect on the early thermal stability of the polymer matrix in all nanocomposites. This effect can be explained by the large number of $\mathrm{OH}$ groups that bare alumina have on its surface. These groups can initiate a process of catalytic degradation of the polysulfone matrix by the formation of highly reactive $\bullet \mathrm{OH}$ free radicals at high temperature, which have the ability to react with organic compounds [32].

3.4. Particle Dispersion by Image Analysis. Figure 4 displays CLSM and FESEM images of PSU_JM (Figures 4(a) and 4(b)) and PSU_Ext composites (Figures 4(c) and 4(d)). Bright regions in Figures 4(a) and 4(c) correspond to light reflection from the surface of alumina particles. It must be pointed out that the nanocomposite shown in Figure 4(a) was prepared with $10 \mathrm{wt} \%$ alumina; even at this high loading, the good homogeneity of these samples can be observed in comparison with nanocomposites prepared by extrusion (Figure 4(c)) at 5\% loading, where the presence of large aggregates is evident. FESEM images in cryogenically fractured samples show the same trend.

Image analysis on CLSM images revealed that the size of aggregates in PSU_Ext samples ranged from 2 to $43 \mu \mathrm{m}$, whereas for jet-milled samples, aggregate average size of $1.0 \pm 0.8 \mu \mathrm{m}$ was found. Therefore, it can be said that jet milling leads to a much better disbanding of aggregates yielding a finer dispersion of smaller particles. This finding confirms the increased interfacial interactions between alumina and PSU which would explain the observed increase in $T_{\mathrm{g}}$. Additionally, the images also demonstrate that shear forces during melt extrusion are not sufficient to break down large agglomerates even with 10 minutes recirculation inside the extruder.

Morphology of low loaded nanocomposites (2 wt.\%) was better achieved by SEM also on cryogenically fractured samples. Figure 5(a) displays the SEM image of neat PSU, 


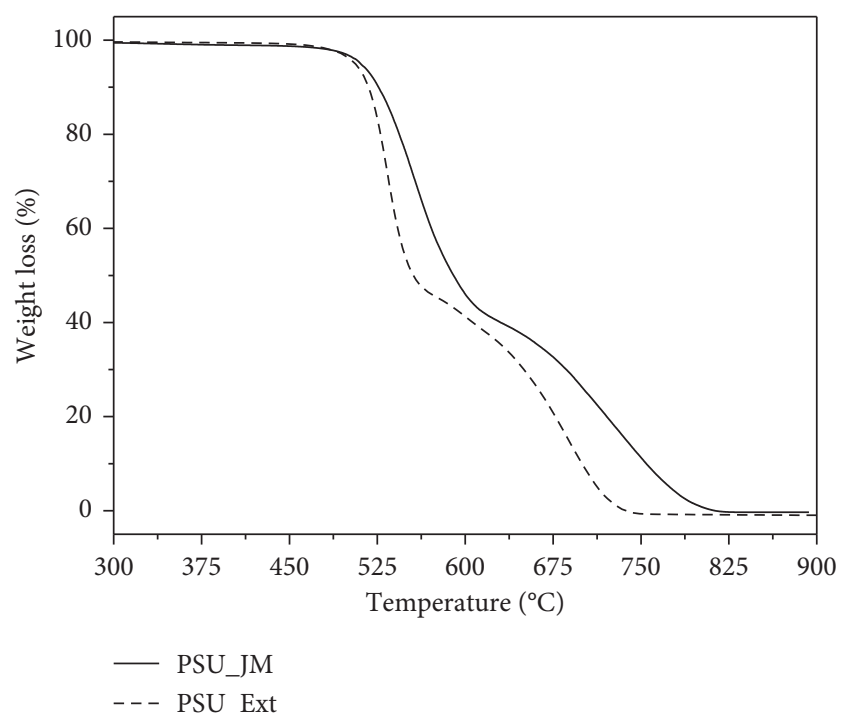

(a)

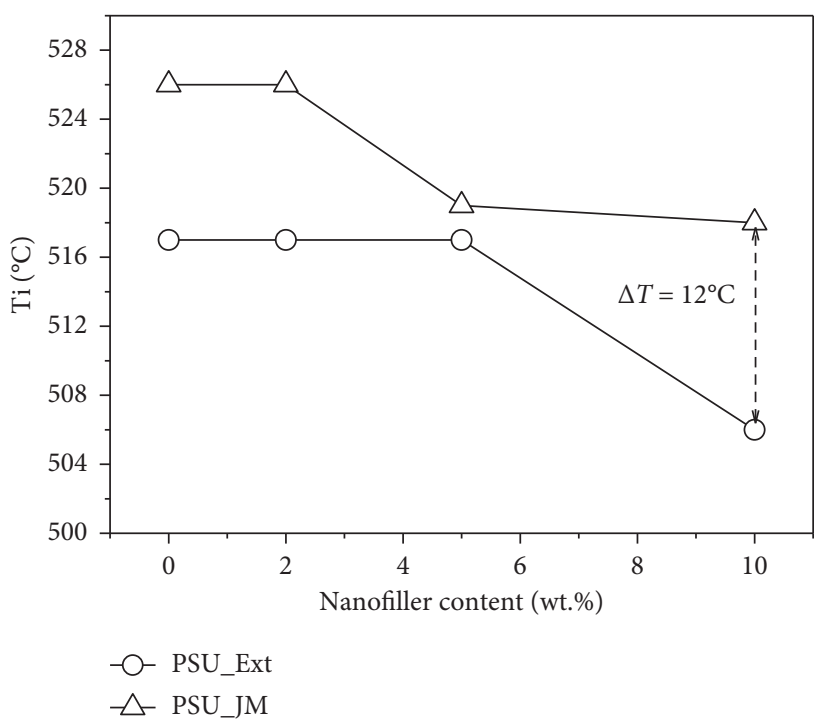

(b)

Figure 3: (a) TGA weight losses versus temperature for PSU_JM and PSU_Ext. (b) Initial decomposition temperature ( $T_{\mathrm{i}}$ ) versus nanofiller content (wt.\%).

TABLE 1: Temperature at the maximum degradation rate $\left(T_{\max }\right)$ for PSU_JM and PSU_Ext as measured at the minimum of the corresponding derivative.

\begin{tabular}{lc}
\hline System & $T_{\max }\left({ }^{\circ} \mathrm{C}\right)$ \\
\hline PSU_JM & 556 \\
PSU2_JM & 572 \\
PSU5_JM & 548 \\
PSU10_JM & 549 \\
PSU_Ext & 533 \\
PSU2_Ext & 537 \\
PSU5_Ext & 533 \\
PSU10_Ext & 526 \\
\hline
\end{tabular}

where the characteristic smooth surface of a brittle surface can be observed. Figures 5(b) and 5(c) show the fractured surfaces of the extruded PSU2_Ext and jet-milled composites, respectively. It was possible to identify large aggregates in the extruded sample, as indicated by the arrows in Figure 5(b). However, finer dispersions were instead observed for jet-milled specimens with aggregate average size less than $1 \mu \mathrm{m}$. It was also possible to observe isolated nanoparticles and aggregates few hundreds of nanometers in size (small primary aggregates) and numerous dimples with protruding edges out of the fracture surface that reflect moderate plastic deformation around the cavities even at cryogenic temperatures. This change in the fracture mechanism clearly indicates the influence of imbibed nanoparticles.

3.5. Tensile Testing. A significant difference in the tensile behavior of the extruded and jet-milled nanocomposites can be observed in Figure 6, where Young's modulus, strength (Figure 6(a)), and ductility (Figure 6(b)), as measured by the strain to failure, are plotted as a function of alumina content. The general trend regardless of the mixing technique indicates that Young's modulus and strength increased modestly with alumina concentration, especially for nanocomposites processed by jet milling, except for the $2 \mathrm{wt} . \%$ extruded sample. In qualitative terms, these results can be explained by the presence of stiff particles (the modulus of alumina is $360 \mathrm{GPa}$ [33]) which controls the overall mechanical response providing stiffer characteristics to the nanocomposites.

However, the most interesting result that can be directly related with dispersion goodness is concerned with ductility (Figure 6(b)). While for extruded samples, ductility monotonically decreased with alumina content, it remained approximately constant for samples processed by jet milling, except for the $2 \mathrm{wt}$ \% sample which slightly decreased. Some authors have explained the reduction of ductility to be a consequence of the reduction in chain mobility. For example, Lu et al. [34] found a decreasing trend in mobility when poly(L-lactide) was doped with $\mathrm{TiO}_{2}$; the observed reduction in ductility was attributed to the adsorption of polymer chains over the surface of the filler. In our case, this explanation is not consistent with our thermal data; as shown in Figure 2, glass transition temperatures decreased with filler content for extruded samples reflecting an increase in chain mobility.

Polysulfone is a tough ductile polymer that deforms under tension by homogeneous shear yielding at room temperature, where yielded material becomes greatly delocalized. However, as stated by Kinloch and Young [35], the deformation mechanism of many polymers can be considered to be a competition between shear yielding, characteristic of ductile polymers, and crazing, a dilatational process that may lead to brittle failure. Within the same polymer, crazing may appear if stress concentration points are induced in the material in such a way that stresses become greatly localized. In this context, badly dispersed large aggregates may act as localized stress concentrators that nucleate microvoids causing 


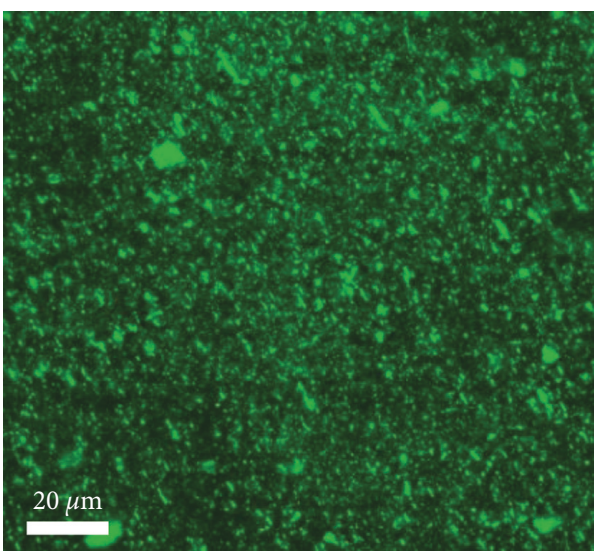

(a)

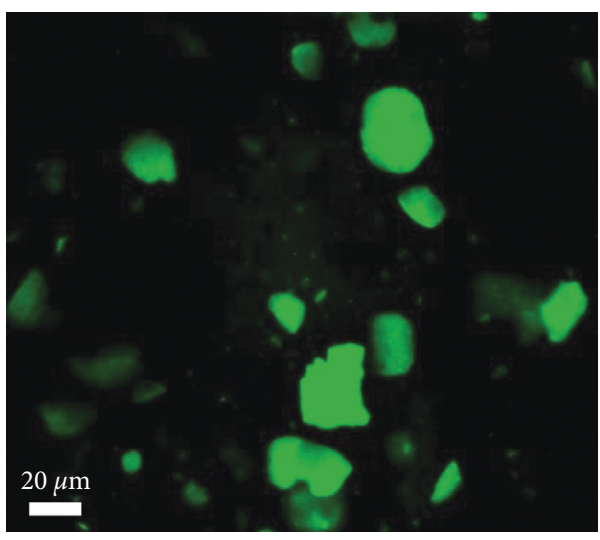

(c)

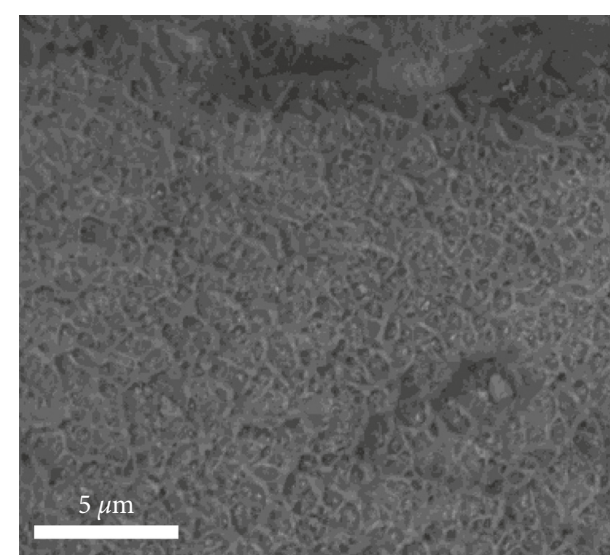

(b)

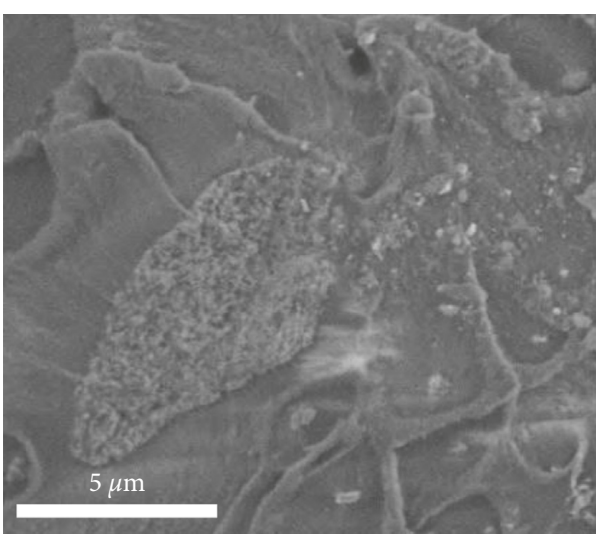

(d)

FIGURE 4: Images of nanocomposites with $10 \mathrm{wt}$ \% alumina prepared by jet milling ((a) LSCM; (b) FESEM) and nanocomposites with 5 wt.\% alumina prepared by extrusion ((c) LSCM; (d) FESEM).
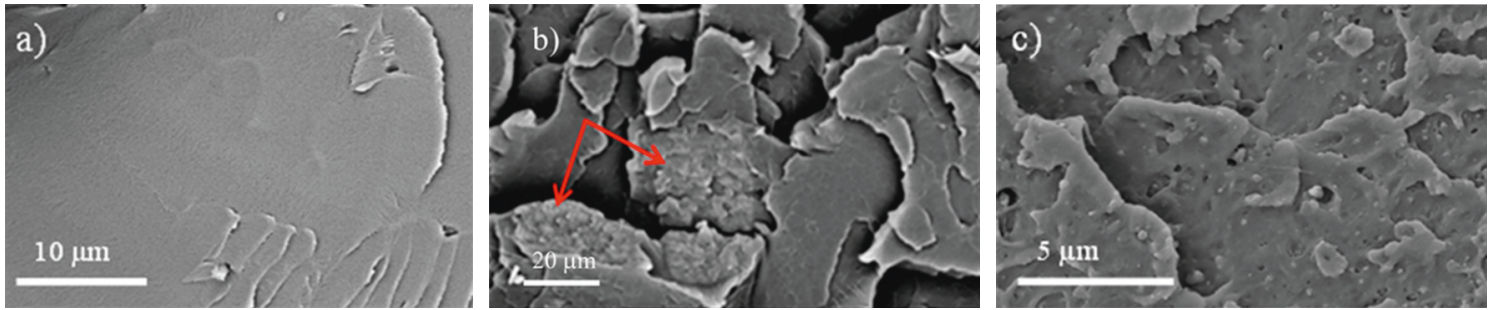

FIGURE 5: SEM images of surface cryofractured of (a) PSU, (b) PSU2_Ext (the arrows show aggregates), and (c) PSU2_JM.

a premature failure of the material. In the case of the nanocomposites prepared by jet milling at high loadings ( $>2$ wt.\%), alumina aggregates may also nucleate microvoids, but since inclusions are very well dispersed, they contribute to the delocalization of the damage and to the stability of the overall deformation process; hence, ductility remains. However, this effect may be highly dependent on the amount of aggregates; low concentration may not be enough to delocalize damage and premature failure may appear. This effect may be the reason for the low value of ductility obtained for the 2 wt.\% sample, i.e., at low loadings, small agglomerates might act as defects within the polymer matrix weakening the overall mechanical response of the nanocomposites.
Similar arguments were employed by Ash et al. [36] to explain the brittle-to-ductile transition observed for some PMMA/alumina nanocomposites.

\section{Conclusions}

A comparative study of the effects of two processing methods: extrusion and jet milling, on the thermal and mechanical properties of PSU/alumina nanocomposites was successfully carried out. The jet milling technique proved to be more successful when compared with extrusion towards preparing nanocomposites with enhanced thermal and mechanical behavior which was strongly related to the dispersion degree of the nanoparticles. The dispersion of 


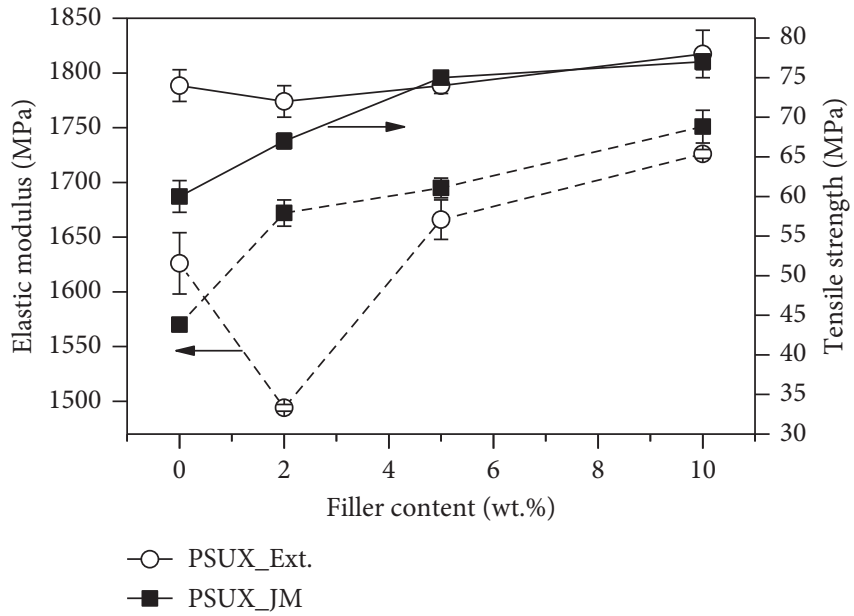

(a)

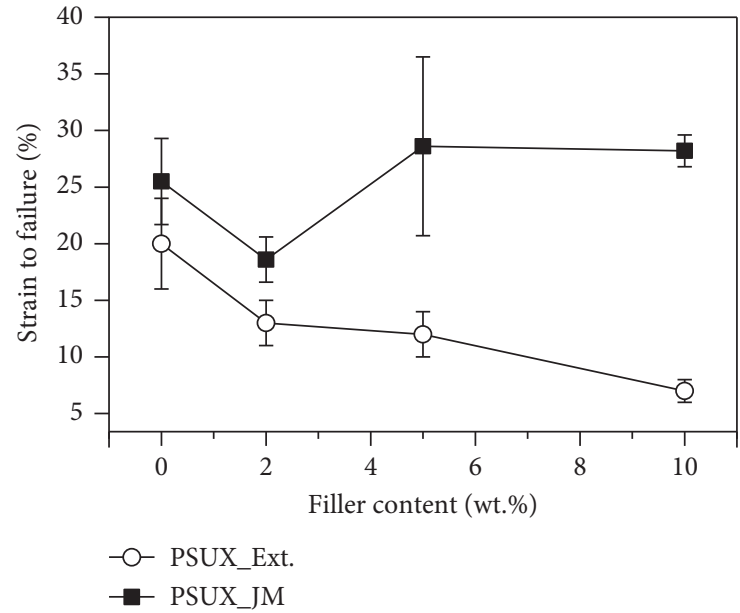

(b)

Figure 6: (a) Elastic modulus (dashed lines), tensile strength (solid lines), and (b) strain to failure as a function of filler content for PSU/ alumina processed by extrusion $(O)$ and jet milling $(\boldsymbol{\square})$.

nanoparticles at both low and high filler concentrations using the jet-milling approach led to a decreased average filler size and an improved dispersion of alumina. Mechanical characterization and fractographical analysis showed enhancements in yield point and modulus of elasticity reflecting the effect of the stiff nanofiller. However, ductility decreased with alumina content for extruded samples but remained almost constant for samples processed by jet milling despite the frequently found embrittlement effect of nanofillers. This behavior was attributed to the extensive delocalization of damage due to the good dispersion state of agglomerates when samples were processed by jet milling. These results strongly suggest that jet milling can be considered as a more efficient and industrially scalable route for preparing polymer nanocomposites when compared with techniques that consider functionalization of nanofillers which is expensive and time consuming.

\section{Data Availability}

Almost all existing data used to support the findings of this study are included within the article. Any additional data are available from the corresponding author upon request.

\section{Conflicts of Interest}

The authors declare that they have no conflicts of interest.

\section{Acknowledgments}

The authors acknowledge funding from Spanish Ministerio de Economía y Competitividad under grant MAT201457557-R. R. Ozisik would like to acknowledge financial support from the US National Science Foundation (CMMI-1538730). The authors also thank I. García and A. Cervera from Euroortodoncia for their invaluable help in nanocomposite processing.

\section{References}

[1] J. Jancar, J. F. Douglas, F. W. Starr et al., "Current issues in research on structure-property relationships in polymer nanocomposites," Polymer, vol. 51, no. 15, pp. 3321-3343, 2010.

[2] Y. Li, T. M. Krentz, L. Wang, B. C. Benicewicz, and L. S. Schadler, "Ligand engineering of polymer nanocomposites: from the simple to the complex," ACS Applied Materials \& Interfaces, vol. 6, no. 9, pp. 6005-6021, 2014.

[3] A. Khabibullin, K. Bhangaonkar, C. L. Mahoney et al., "Grafting PMMA brushes from $\alpha$-alumina nanoparticles via SI-ATRP,” ACS Applied Materials \& Interfaces, vol. 8, no. 8, pp. 5458-5465, 2016.

[4] M. M. Khani, D. Woo, E. L. Mumpower, and B. C. Benicewicz, "Poly(alkyl methacrylate)-grafted silica nanoparticles in polyethylene nanocomposites," Polymer, vol. 109, pp. 339348, 2017.

[5] A. Llorente, B. Serrano, and J. Baselga, "The effect of polymer grafting in the dispersibility of alumina/polysulfone nanocomposites," Macromolecular Research, vol. 25, no. 1, 2017.

[6] R. Yokoyama, S. Suzuki, K. Shirai, T. Yamauchi, N. Tsubokawa, and M. Tsuchimochi, "Preparation and properties of biocompatible polymer-grafted silica nanoparticle," European Polymer Journal, vol. 42, no. 12, pp. 3221-3229, 2006.

[7] S. K. Kumar, N. Jouault, B. Benicewicz, and T. Neely, "Nanocomposites with polymer grafted nanoparticles," Macromolecules, vol. 46, no. 9, pp. 3199-3214, 2013.

[8] M. J. Hamer, B. V. S. Iyer, V. V. Yashin, T. Kowalewski, K. Matyjaszewski, and A. C. Balazs, "Modeling polymer grafted nanoparticle networks reinforced by high-strength chains," Soft Matter, vol. 10, no. 9, pp. 1374-1383, 2014.

[9] A. Rungta, B. Natarajan, T. Neely, D. Dukes, L. S. Schadler, and B. C. Benicewicz, "Grafting bimodal polymer brushes on nanoparticles using controlled radical polymerization," Macromolecules, vol. 45, no. 23, pp. 9303-9311, 2012.

[10] D. Sunday, J. Ilavsky, and D. L. Green, "A phase diagram for polymer-grafted nanoparticles in homopolymer matrices," Macromolecules, vol. 45, no. 9, pp. 4007-4011, 2012. 
[11] P.-C. Ma, N. A. Siddiqui, G. Marom, and J.-K. Kim, "Dispersion and functionalization of carbon nanotubes for polymer-based nanocomposites: a review," Composites Part A: Applied Science and Manufacturing, vol. 41, no. 10, pp. 1345-1367, 2010.

[12] J. i. Masuda and J. M. Torkelson, "Dispersion and major property enhancements in polymer/multiwall carbon nanotube nanocomposites via solid-state shear pulverization followed by melt mixing," Macromolecules, vol. 41, no. 16, pp. 5974-5977, 2008.

[13] K. A. Iyer and J. M. Torkelson, "Importance of superior dispersion versus filler surface modification in producing robust polymer nanocomposites: the example of polypropylene/ nanosilica hybrids," Polymer, vol. 68, pp. 147-157, 2015.

[14] K. A. Iyer, A. M. Flores, and J. M. Torkelson, "Comparison of polyolefin biocomposites prepared with waste cardboard, microcrystalline cellulose, and cellulose nanocrystals via solid-state shear pulverization," Polymer, vol. 75, pp. 78-87, 2015.

[15] K. A. Iyer, G. T. Schueneman, and J. M. Torkelson, “Cellulose nanocrystal/polyolefin biocomposites prepared by solid-state shear pulverization: superior dispersion leading to synergistic property enhancements," Polymer, vol. 56, pp. 464-475, 2015.

[16] K. A. Iyer, J. Lechanski, and J. M. Torkelson, "Green polypropylene/waste paper composites with superior modulus and crystallization behavior: optimizing specific energy in solid-state shear pulverization for filler size reduction and dispersion," Composites Part A: Applied Science and Manufacturing, vol. 83, pp. 47-55, 2016.

[17] J. Folkes, "Waterjet-an innovative tool for manufacturing," Journal of Materials Processing Technology, vol. 209, no. 20, pp. 6181-6189, 2009.

[18] S. Palaniandy, K. Azizi Mohd Azizli, H. Hussin, and S. Fuad Saiyid Hashim, "Mechanochemistry of silica on jet milling," Journal of Materials Processing Technology, vol. 205, no. 1-3, pp. 119-127, 2008.

[19] W. G. Sawyer, K. D. Freudenberg, P. Bhimaraj, and L. S. Schadler, "A study on the friction and wear behavior of PTFE filled with alumina nanoparticles," Wear, vol. 254, no. 5-6, pp. 573-580, 2003.

[20] S. Anaya, S. Berna, A. C. Berta Herrero, and J. Baselga, " $\gamma$-alumina modification with long chain carboxylic acid surface nanocrystals for biocompatible polysulfone nanocomposites," ACS Applied Materials \& Interfaces, vol. 6, no. 16, pp. 14460-14468, 2014.

[21] D. L. Burris, S. Zhao, R. Duncan et al., "A route to wear resistant PTFE via trace loadings of functionalized nanofillers," Wear, vol. 267, no. 1-4, pp. 653-660, 2009.

[22] D. L. Burris and W. G. Sawyer, Effects of Nanoparticles on the Wear Resistance of Polytetrafluoroethylene, University of Florida, Gainesville, FL, USA, 2007.

[23] G. Gedler, M. Antunes, and J. I. Velasco, "Viscoelastic properties of polycarbonate-graphene nanoplatelets nanocomposite foams," Composites Part B: Engineering, vol. 93, pp. 143-152, 2016.

[24] R. Y. Hong and Q. Chen, "Dispersion of inorganic nanoparticles in polymer matrices: challenges and solutions," Advances in Polymer Science, vol. 267, pp. 1-38, 2015.

[25] A. Sorrentino, G. Gorrasi, M. Tortora et al., "Incorporation of $\mathrm{Mg}$-Al hydrotalcite into a biodegradable poly( $\varepsilon$-caprolactone) by high energy ball milling," Polymer, vol. 46, no. 5, pp. 1601-1608, 2005.

[26] F. Mammeri, E. Le Bourhis, L. Rozes, and C. Sanchez, "Elaboration and mechanical characterization of nanocomposites thin films," Journal of the European Ceramic Society, vol. 26, no. 3, pp. 259-266, 2006.

[27] B. J. Ash, L. S. Schadler, and R. W. Siegel, "Glass transition behavior of alumina/polymethylmethacrylate nanocomposites," Materials Letters, vol. 55, no. 1-2, pp. 83-87, 2002.

[28] H. S. Vaziri, I. A. Omaraei, M. Abadyan, M. Mortezaei, and N. Yousefi, "Thermophysical and rheological behavior of polystyrene/silica nanocomposites: investigation of nanoparticle content," Materials \& Design, vol. 32, no. 8-9, pp. 4537-4542, 2011.

[29] S. Wu, "Chain structure, phase morphology, and toughness relationships in polymers and blends," Polymer Engineering and Science, vol. 30, no. 13, pp. 753-761, 1990.

[30] T. Orhan, S. Ates, J. Hacaloglu, and Y. Yagci, "Thermal degradation characteristics of polysulfones with benzoxazine end groups," Journal of Analytical and Applied Pyrolysis, vol. 94, pp. 146-152, 2012.

[31] G. Molnár, A. Botvay, L. Pöppl et al., "Thermal degradation of chemically modified polysulfones," Polymer Degradation and Stability, vol. 89, no. 3, pp. 410-417, 2005.

[32] R. Munter, "Advanced oxidation processes-current status and prospects," Proceedings of the Estonian Academy of Sciences, Chemistry, vol. 50, pp. 59-80, 2001.

[33] G. V. Samsonov, The Oxide Handbook, IFI/Plenum, New York, NY, USA, 1983.

[34] X. Lu, X. Lv, Z. Sun, and Y. Zheng, "Nanocomposites of poly(L-lactide) and surface-grafted $\mathrm{TiO}_{2}$ nanoparticles: synthesis and characterization," European Polymer Journal, vol. 44, no. 8, pp. 2476-2481, 2008.

[35] A. J. Kinloch and R. J. Young, Fracture Behaviour of Polymers, Elsevier, London, UK, 1990.

[36] B. J. Ash, R. W. Siegel, and L. S. Schadler, "Glass-transition temperature behavior of alumina/PMMA nanocomposites," Journal of Polymer Science Part B: Polymer Physics, vol. 42, no. 23 , pp. 4371-4383, 2004. 


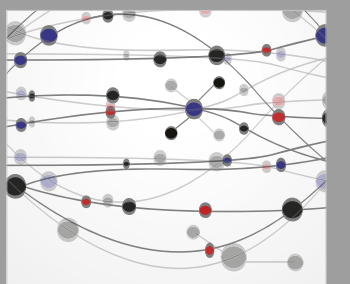

The Scientific World Journal
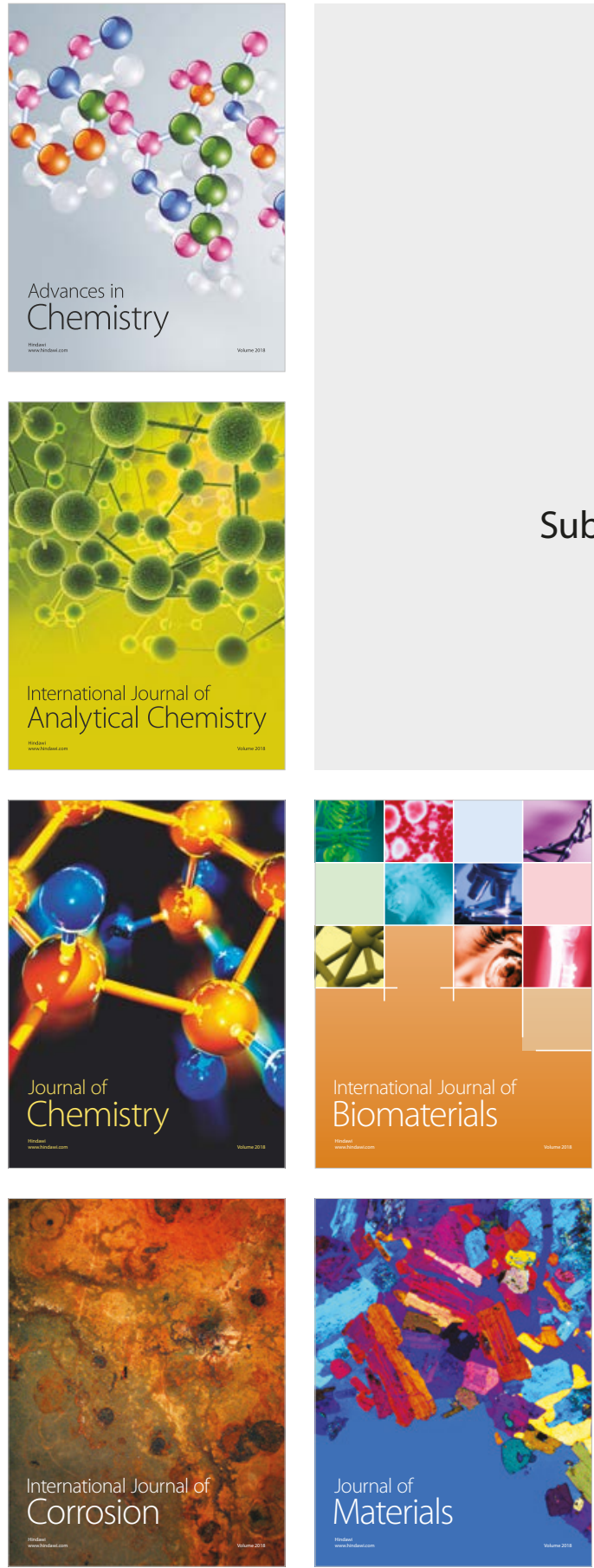

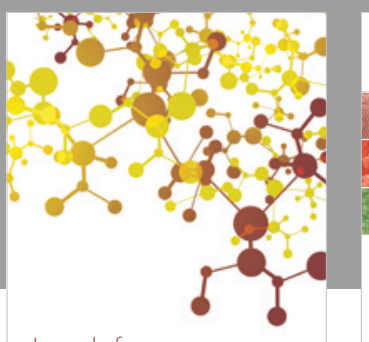

Journal of

Applied Chemistry
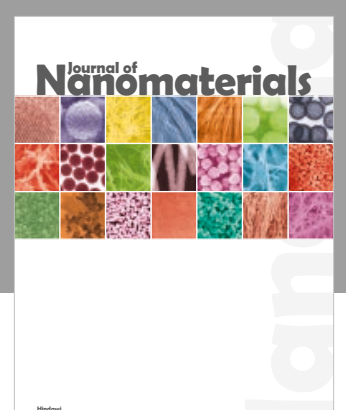

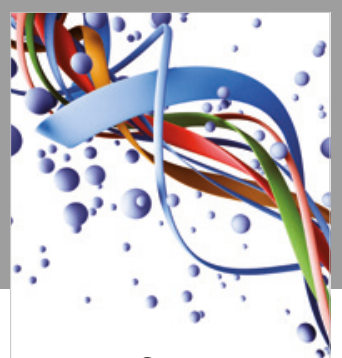

Scientifica

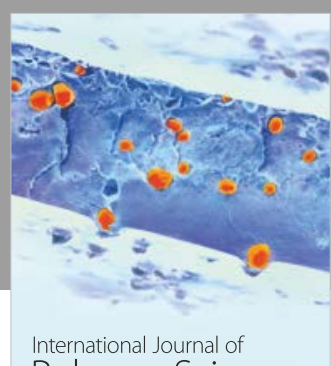

Polymer Science

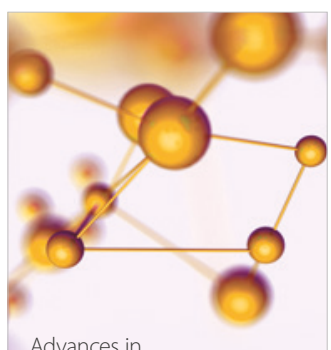

Physical Chemistry
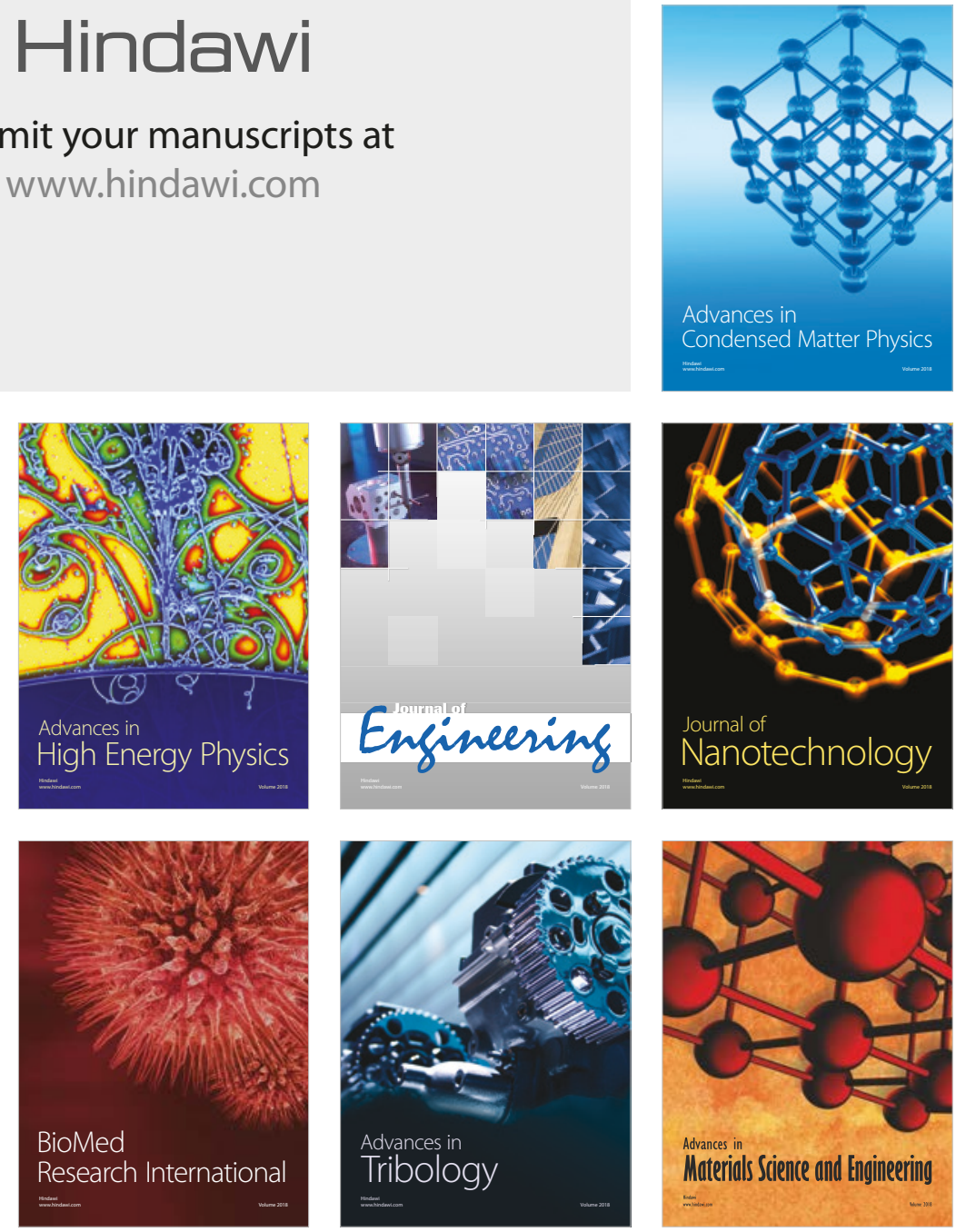